\title{
Depression Screening Rates and Symptom Severity by Alcohol Use Among Primary Care Adult Patients
}

\author{
Matthew E. Hirschtritt, MD, MPH, Andrea H. Kline-Simon, MS, Kurt Kroenke, MD, \\ Stacy A. Sterling, DrPH, MPH, MSW
}

Background: Hazardous alcohol use with depression may exacerbate health conditions and complicate medical care. We examined the rate of depression screening by alcohol use severity among primary care patients screened for hazardous alcohol use and, among those screened, examined patterns of significant depressive symptoms.

Methods: Using cross-sectional data from primary care patients $(n=2,894,906)$, we examined past-90day alcohol use (number of typical drinking days/week and typical number of drinks consumed daily); depression screening rates (using the Patient Health Questionnaire 9 [PHQ-9]); and symptom severity, demographics, and prevalence of selected psychiatric diagnoses.

Results: Within 30 days of routine, in-clinic alcohol use screening by medical assistants, $2.4 \%$ (n = $\mathbf{6 8 , 6 8 6}$ ) of patients also completed a PHQ-9; these patients were more likely to be female, younger, white, Medicaid insured, and to have a nondepressive psychiatric diagnosis and a lower Charlson comorbidity score. Abstainers and moderate drinkers (1 to 7 drinks/week or 1 to 4 drinks/week for women and individuals $>65$ years or for men $\leq 65$ years, respectively) were less likely than hazardous drinkers (exceeding weekly limits) to complete the PHQ-9 or to have significant depressive symptoms (PHQ-9 score $\geq 10$ ). Nonwhite patients with higher Charlson comorbidity scores were more likely to endorse significant depressive symptoms.

Conclusions: Only a small fraction of patients in this cohort were screened for depression. Nonwhite patients and those with higher comorbidity burden were more likely to report depression but less likely to be screened. These discrepancies between depression-screening rates and significant depressive symptoms suggest that screening for depression should be enhanced in these at-risk groups. ( $\mathrm{J}$ Am Board Fam Med 2018;31:724-732.)

Keywords: Comorbidity, Cross Sectional Analysis, Depression, Patient Health Questionnaire, Primary Health Car

The prevalence of significant depressive symptoms within the past 2 weeks among adults in the United States is approximately $8.1 \%,{ }^{1}$ and $21.6 \%$ had some depressive symptoms; ${ }^{2}$ for comparison, the prevalence of diagnosed diabetes among US adults

This article was externally peer reviewed.

Submitted 22 March 2018; revised 29 May 2018; accepted 1 June 2018.

From Department of Psychiatry, Weill Institute for Neurosciences, University of California, San Francisco, CA (MEH); Division of Research, Kaiser Permanente Northern California, Oakland (AHK-S, SAS); Indiana University School of Medicine, Regenstrief Institute, Inc., Indianapolis, IN (KK).

Funding: This research was supported by a grant from the National Institute on Alcohol Abuse and Alcoholism to Dr. Sterling (grant R01-AA025902-01) and a training grant from the National Institute of Mental Health to Dr. Hirschtritt (grant R25-MH060482-17).

Conflict of interest: none declared. is $9.4 \% .^{3}$ In primary care settings alone, $6.0 \%$ of adults may meet criteria for a major depressive episode. ${ }^{4}$ Furthermore, depressive symptoms may complicate medical conditions, including reducing medication compliance ${ }^{5}$ and exacerbating physical disability, ${ }^{6}$ leading to overall worse health outcomes. Therefore, the US Preventive Services Task Force (USPSTF) recommends screening "all adults who have not been screened previously" for depression in primary care by using a standardized instrument, such as the Patient Health Questionnaire 9

Corresponding author: Matthew E. Hirschtritt, MD, MPH, Department of Psychiatry, Weill Institute for Neurosciences, University of California, San Francisco, 401 Parnassus Avenue, Box 0984, San Francisco, CA 94143 (E-mail: matthew.hirschtritt@ucsf.edu). 
(PHQ-9), with adequate resources in place for accurate diagnosis and appropriate treatment and follow-up care. ${ }^{7}$ However, as recently as 2013, the rate of US primary care-based depression screening was only $4.2 \% .^{8}$

Similarly, hazardous alcohol use, which the USPSTF defines as "consumption of alcohol above recommended daily, weekly, or per-occasion amounts" (ie, $>14$ drinks/week or $>4$ drinks/day for men 65 years or younger, and $>7$ drinks/week or $>3$ drinks/day for women of any age and for men older than 65 years), ${ }^{9}$ is prevalent in primary care settings. Although those who meet criteria for an alcohol use disorder (AUD) may exhibit symptoms that are detected in primary care, nearly $90 \%$ of hazardous drinkers would not meet criteria for a severe AUD, ${ }^{10}$ and may therefore escape clinical attention. Between $7.5 \%$ and $20 \%$ of adult primary care patients exhibit hazardous alcohol use, ${ }^{11,12}$ which is associated with multiple medical (eg, liver cirrhosis, esophageal and breast cancer) and social (eg, domestic violence, revocation of driver's license) consequences. ${ }^{13}$ In 2010 alone, excessive drinking (defined as binge drinking [ $\geq 4$ drinks/ occasion for women, $\geq 5$ drinks/occasion for men], heavy drinking $[\geq 8$ drinks/week for women, $\geq 15$ for men], or any alcohol use by individuals younger than 21 years or pregnant) cost the United States $\$ 249$ billion. ${ }^{14}$ In this context, the USPSTF recommends screening all adults ages 18 years or older for alcohol misuse and, for those with alcohol misuse, engagement in brief behavioral counseling. ${ }^{15}$ The screening, brief intervention and referral to treatment model, an example of such an effort, aims to identify and intervene with primary care patients with hazardous alcohol use. ${ }^{16}$ Based on available evidence, the USPSTF recommends screening using self-report questionnaires with high validity in primary care settings, such as the 10-item Alcohol Use Disorders Identification Test (AUDIT) ${ }^{17}$ or the abbreviated 3-item AUDIT-Consumption $\left(\right.$ AUDIT-C) ${ }^{18}$, or a single-item screening question (eg, "How many times in the past year have you had 5 [for men age 65 or younger] or 4 [for women and all adults older than 65 years] or more drinks in a day?”). ${ }^{16}$ However, clinician detection of alcoholuse problems in primary care remains low (only $41.7 \%$ of clinicians were able to accurately detect alcohol-use problems compared with a reference standard in the most recent meta-analysis on this topic), ${ }^{19}$ and successful referral to treatment is similarly low. ${ }^{20}$

Depressive symptoms frequently co-occur with alcohol problems. For example, adults with an AUD, compared with those who have never met criteria for AUD, are nearly twice as likely to have also met criteria for lifetime major depressive disorder ${ }^{21}$ likewise, among adults with a depressive disorder in the past 12 months, as many as $14 \%$ may have had an AUD. ${ }^{22}$ A systematic review of 35 studies that examined "alcohol problems" (defined as at-risk, hazardous, or harmful drinking; alcohol abuse; alcohol dependence; or alcoholism) among adults with depression demonstrated a median prevalence of current and lifetime alcohol problems of $16 \%$ (range, $5 \%$ to $76 \%$ ) and $30 \%$ (range, $10 \%$ to $60 \%$ ), respectively. ${ }^{23}$ This wide variability in prevalence estimates is likely a result of varying methods used to measure alcohol problems and depression (eg, semistructured interviews, selfreport forms), diverse populations (eg, inpatient psychiatric settings, outpatient primary care), and inclusion criteria (eg, exclusion of patients with other substance use disorders [SUDs]). Of note, only one of the studies reported by this review defined alcohol problems as "at-risk drinking" (total score $\geq 2$ on the Short Michigan Alcohol Screening Test-Geriatric Version $\left.{ }^{24}\right){ }^{25}$ the remainder examined the prevalence of more severe alcohol use problems (ie, alcohol abuse, dependence, or alcoholism). A more recent review examining the association between AUDs and major depression ${ }^{26}$ yielded 15 studies, 6 of which examined hazardous drinking by using disparate definitions, including drinking $>5$ drinks in a single occasion over the past month, ${ }^{27}$ highest subgroup of alcohol consumers, ${ }^{28,29}$ and exceeding a threshold on a self-report measure. ${ }^{30}$ Among all 15 studies, the adjusted odds ratio (OR) of major depression among patients with an AUD was 2.00 (95\% confidence interval [CI], 1.19 to 3.35$)$, and the adjusted OR of AUD among patients with major depression was 2.09 (95\% CI, 1.29 to 3.38$){ }^{26}$

Comorbid hazardous alcohol use and depression confer higher risks of self-harm and suicide ${ }^{31}$ than either condition alone; likewise, hazardous alcohol use may exacerbate the symptoms of depression ${ }^{26}$ and decrease treatment adherence. In addition, comorbidity of hazardous alcohol use and depression has important treatment implications; for instance, in a randomized trial comparing usual care with a 
quality-improvement program for adults with major depression with or without substance misuse (including hazardous alcohol use), those with comorbid substance misuse demonstrated improvement in measures of depression severity at 6 and 12 months postbaseline. ${ }^{32}$ However, those with comorbid hazardous alcohol use and depression (compared with depression alone) may exhibit more severe depressive symptoms at baseline and follow-up despite improvements with tailored interventions. ${ }^{33}$ Nonetheless, a minority of patients with depression and hazardous alcohol use report receiving counseling from their primary care provider; in one study, only $14 \%$ (26\% of men, $5 \%$ of women) of these patients reported receiving counseling about their alcohol use. ${ }^{34,35}$

Despite the strong association between depressive symptoms and hazardous alcohol use, there are no data of which we are aware regarding rates of depression screening by alcohol use severity and demographic characteristics in primary care settings. This information would inform systematic efforts to detect and design tailored treatments for patients with significant depressive symptoms and hazardous alcohol use. Therefore, using cross-sectional data from a screening, brief intervention, and referral to treatment initiative implemented in Kaiser Permanente of Northern California (KPNC) primary care clinics, we sought to assess rates of PHQ-9 administration by drinking severity, and among patients who completed the PHQ-9, to examine the association between depressive-symptomatology and drinking severity. We hypothesized that more severe alcohol use would be associated with higher rates of PHQ-9 administration and correspondingly higher depressive-symptom ratings.

\section{Methods}

Among KPNC primary care patients (ages $\geq 18$ years) who participated in an alcohol screening and brief intervention initiative (Alcohol as a Vital Sign ${ }^{36}$ ), we examined whether the PHQ- $9^{37}$ had been administered and, if so, whether the total score met the threshold for significant depressive symptoms. A total score of $\geq 10$ was chosen as the threshold for significant depression; this threshold is associated with a sensitivity of 0.77 (95\% CI, $0.66-0.85)$ and a specificity of 0.85 (95\% CI, 0.790.90 ) for major depression. ${ }^{38}$ The PHQ-9 is recommended specifically by the USPSTF ${ }^{39}$ and is part of the mental health screening instrument in KPNC. The PHQ-2 was not offered to patients; in primary care settings, a threshold of 10 on the PHQ-9 demonstrates similar sensitivity and higher sensitivity for major depression compared with a threshold of 2 or 3 on the PHQ-2. ${ }^{40}$ KPNC's and the University of California San Francisco's institutional review boards approved this study.

We extracted data from the electronic health record for the first primary care visit among all adult patients between November 1, 2014, and December 31, 2016, including sex, age, self-reported race/ethnicity, Medicaid primary insurance (an indicator of socioeconomic status), the presence of a nondepressive or nonsubstance use-related mental health diagnosis within the prior year, alcohol use severity, and PHQ-9 total score. In addition, we estimated patients' comorbidity burden by using the Charlson comorbidity score; this measure consists of a weighted score of 17 conditions and predicts the risk of 1-year mortality for patients with a range of these diagnosis-based comorbid conditions. ${ }^{41-43}$ We included the first PHQ-9 administration within 30 days of the index visit for each patient to account for any possible delay between a clinician's recognition of hazardous alcohol use (from the previsit screener) and administration of the PHQ-9 (which the clinician may have asked the patient to complete remotely following the visit on the electronic patient portal or in a follow-up visit). Because depressive disorder diagnoses and abovethreshold PHQ-9 scores are highly correlated, we excluded depressive disorders (present in $6.1 \%$ of this sample) from the omnibus mental health diagnosis variable. Similarly, we excluded substance use-related diagnoses (the majority of which consisted of AUDs) because of the high correlation between these diagnoses and our alcohol use-severity variable.

During the previsit rooming process, medical assistants asked patients the following: (1) the mean number of days/week they consumed alcohol and (2) how many alcoholic drinks they consumed "on a typical drinking day" over the past 90 days. Using these data, we calculated the mean number of alcoholic drinks consumed weekly (ie, mean number of drinking days/week multiplied by the number of drinks consumed on a typical drinking day). Based on guidelines established by the National Institute on Alcohol Abuse and Alcoholism, ${ }^{16}$ we defined drinking severity as "abstinent" (no alcohol con- 
sumption), "moderate alcohol use" (1 to 14 drinks/ week for men $\leq 65$ years and 1 to 7 drinks/week for women of any age and for men $>65$ ), and "hazardous alcohol use" ( $>14$ drinks/week for men $\leq 65$ years and $>7$ drinks/week for women and for men $>65$ ).

\section{Statistical Analysis}

We applied $\chi^{2}$ and $t$ tests to examine differences in categorical and continuous patient characteristic variables (including alcohol use severity) by PHQ-9 screening administration and among those who were administered the PHQ-9, the presence of significant depressive symptoms. Because patients were nested within facility, generalized estimating equation techniques were used to fit multivariable logistic regression models clustered on health care facility to evaluate the OR of PHQ-9 administration by patient characteristics. Among those who were administered the PHQ-9, the OR of significant depressive symptoms by patient characteristics were also calculated. As an aim of this study was to examine rates of PHQ-9 administration, missing PHQ-9 values were not imputed; demographic and clinical characteristics were available for all patients included in this analysis.

\section{Results}

Of all patients screened for hazardous alcohol use ( $\mathrm{n}=2,894,906$, representing $88 \%$ of all primary care visits within the study period), $2.4 \%$ ( $\mathrm{n}=$ 68,686) were administered the PHQ-9 within 30 days of their first alcohol-use screening (Table 1). The following patient characteristics were associated with more frequent PHQ-9 administration: female sex (compared with male sex), age 18 to 39 years (compared with ages 40 to 65 and $>65$ years), white race/ethnicity (compared with all other racial/ethnic groups), Medicaid coverage (compared with those without Medicaid coverage [eg, commercial insurance or Medicare]), presence of a nondepressive/non-SUD mental health diagnosis, lower Charlson comorbidity score, and abstinence from alcohol use (compared with moderate and hazardous alcohol use) $(P<.001$ for all comparisons). Among those who received PHQ-9 screening, $47.2 \%(\mathrm{n}=32,390)$ endorsed significant depressive symptoms in the past 2 weeks (Table 1). Patterns of significant depressive symptoms by patient characteristics were similar to those of
PHQ-9 administration for all variables listed above (with $P<.001$ for all comparisons), with the exception of the presence of a nondepressive/nonSUD mental health diagnosis $(P=.751)$.

In generalized estimating equation models, patients who were female, younger, white, covered by Medicaid, had a nondepressive/non-SUD mental health diagnosis, had a lower Charlson comorbidity score, and endorsed hazardous alcohol use demonstrated higher ORs of PHQ-9 administration $(P<$ .001 for all models) (Table 2). Among patients administered the PHQ-9, the direction and significance of the ORs associated with significant depressive symptoms were similar to those for PHQ-9 administration for all patient characteristics except race/ethnicity (all groups except Asian patients were more likely than white patients to endorse significant depressive symptoms) and Charlson comorbidity score (higher scores were associated with higher OR of significant depressive symptoms); the presence of a nondepressive/nonSUD mental health diagnosis was not significantly associated with depressive symptoms.

\section{Discussion}

In a large and diverse sample of primary care patients screened for hazardous alcohol use, only $2.4 \%$ were also administered a standardized depression-screening instrument. This fraction is much lower than would be expected given current recommendations for depression screening in primary care settings. ${ }^{7}$ However, the observed rate of depression screening in this sample is roughly consistent with rates in other primary-care samples. Furthermore, nonwhite and more medically ill patients were less likely to be screened for depression compared with white and less medically ill patients but, when screened, were more likely to endorse significant depressive symptoms. However, as hypothesized, patients who reported abstinence or moderate alcohol use were less likely than those reporting hazardous alcohol use to be administered the PHQ-9 and to endorse significant depressive symptoms.

The high rate of alcohol-use screening (88\%) in this sample, in contrast to the low absolute rate of PHQ-9 administration (2.4\%), is most likely a reflection of a systematic initiative to encourage universal alcohol-use screening. In contrast, the PHQ-9 was offered for physicians to administer as 
Table 1. Demographic and Clinical Characteristics by Depression Screening Status among Primary Care Adult Patients Screened for Hazardous Alcohol Use

\begin{tabular}{|c|c|c|c|c|c|c|}
\hline \multirow[b]{2}{*}{ Characteristic } & \multicolumn{2}{|c|}{ No. (\%) } & \multirow[b]{2}{*}{$\begin{array}{c}P \\
\text { value }\end{array}$} & \multicolumn{2}{|c|}{ No. (\%) } & \multirow[b]{2}{*}{$P$ value } \\
\hline & $\begin{array}{l}\text { Administered } \\
\text { the PHQ-9 }\end{array}$ & $\begin{array}{c}\text { Not } \\
\text { Administered } \\
\text { the PHQ-9 }\end{array}$ & & $\begin{array}{l}\text { Met Criteria } \\
\text { for } \\
\text { Significant } \\
\text { Depression }\end{array}$ & $\begin{array}{c}\text { Did Not } \\
\text { Meet Criteria } \\
\text { for } \\
\text { Significant } \\
\text { Depression }\end{array}$ & \\
\hline Totals & $(\mathrm{n}=68,686)^{*}$ & $(\mathrm{n}=2,826,220)^{*}$ & & $(\mathrm{n}=32,390)^{\dagger}$ & $(\mathrm{n}=36,296)^{\dagger}$ & \\
\hline Sex & & & $<.001$ & & & $<.001$ \\
\hline Female & $45,007(65.5)$ & $1,505,142(53.3)$ & & $21,715(67.0)$ & $23,292(64.2)$ & \\
\hline Male & $23,679(34.5)$ & $1,321,078(46.7)$ & & $10,675(33.0)$ & $13,004(35.8)$ & \\
\hline Age, years & & & $<.001$ & & & $<.001$ \\
\hline 18 to 39 & $32,295(47.0)$ & $1,081,490(38.3)$ & & $17,017(52.5)$ & $15,278(42.1)$ & \\
\hline 40 to 65 & $27,980(40.8)$ & $1,213,142(42.9)$ & & $12,546(38.7)$ & $15,434(42.5)$ & \\
\hline$>65$ & $8,411(12.2)$ & $531,588(18.8)$ & & $2,827(8.7)$ & $5,584(15.4)$ & \\
\hline Race/ethnicity $^{\ddagger}$ & & & $<.001$ & & & $<.001$ \\
\hline Asian & $6,619(9.6)$ & $525,505(18.6)$ & & $3,169(9.8)$ & $3,450(9.5)$ & \\
\hline $\begin{array}{l}\text { Black/African } \\
\text { American }\end{array}$ & $4,348(6.3)$ & $200,530(7.1)$ & & $2,525(7.8)$ & $1,823(5.0)$ & \\
\hline Hispanic & $14,194(20.7)$ & $554,523(19.6)$ & & 7,425 (22.9) & $6,769(18.7)$ & \\
\hline White & $39,035(56.8)$ & $1,351,540(47.8)$ & & $17,013(52.5)$ & $22,022(60.7)$ & \\
\hline Other/Unknown & $4,490(6.5)$ & $194,122(6.9)$ & & $2,258(7.0)$ & $2,232(6.2)$ & \\
\hline Medicaid coverage & & & $<.001$ & & & $<.001$ \\
\hline Yes & $1,066(1.6)$ & $29,347(1.0)$ & & $632(2.0)$ & $434(1.2)$ & \\
\hline No & $67,620(98.4)$ & 2,796,873 (99.0) & & $31,758(98.0)$ & $35,862(98.8)$ & \\
\hline $\begin{array}{l}\text { Nondepressive/non-SUD } \\
\text { mental health } \\
\text { diagnosis }^{\S}\end{array}$ & & & $<.001$ & & & .751 \\
\hline Yes & $4,628(6.7)$ & $138,773(4.9)$ & & $2,172(6.7)$ & $2,456(6.8)$ & \\
\hline No & $64,058(93.3)$ & $2,687,447(95.1)$ & & $30,218(93.3)$ & $33,840(93.2)$ & \\
\hline $\begin{array}{l}\text { Charlson comorbidity } \\
\text { score, mean (SD) }\end{array}$ & $0.29(0.95)$ & $0.41(1.15)$ & $<.001$ & $0.27(0.91)$ & $0.31(0.98)$ & $<.001$ \\
\hline Weekly alcohol use \| & & & $<.001$ & & & $<.001$ \\
\hline Abstinent & $45,468(66.2)$ & $1,949,582(69.0)$ & & $22,069(68.1)$ & $23,399(64.5)$ & \\
\hline Moderate alcohol use ${ }^{* *}$ & $19,189(27.9)$ & $764,294(27.0)$ & & $8,275(25.6)$ & $10,914(30.1)$ & \\
\hline $\begin{array}{l}\text { Hazardous alcohol } \\
\text { use }^{\dagger \dagger}\end{array}$ & $4,029(5.9)$ & $112,344(4.0)$ & & $2,046(6.3)$ & $1,983(5.5)$ & \\
\hline
\end{tabular}

PHQ-9, Patient Health Questionnaire 9; SUD, substance use disorder; ICD-9, International Classification of Diseases, ninth revision; SD, standard deviation.

*Data were restricted to the first PHQ-9 administration within 30 days following the first Alcohol Drinking as a Vital Sign primary care visit within the study period.

${ }^{\dagger}$ Among patients who were administered the PHQ-9 $(\mathrm{n}=68,686)$.

${ }^{\ddagger}$ Race/ethnicity data were self-reported by patients during their intake evaluation.

${ }^{\S}$ Any ICD-9 visit diagnosis code within 1 year prior to the first Alcohol Drinking as a Vital Sign primary care visit that adhered to the following criteria was considered a positive diagnosis: any mental, behavioral and neurodevelopmental disorder (290.XX, 293.XX, 294.XX-302.9, or 306.XX-319), excluding depressive disorders (296.2X, 296.3X, 296.82, 298.0, 300.4, 301.12, 309.0, 309.1, 309.28, or 311), alcohol-related mental disorders (291.XX, 305.0X, or 303.0X), drug-induced mental disorders (292.XX), and nontobacco drug abuse or dependence (305.2X, 305.3X, 305.4X, 305.5X, 306.6X, 305.7X, 305.8X, 305.9X, or 304.XX), where "X" represents any positive integer.

$\|$ Patients were asked to estimate alcohol use within the past 90 days.

${ }^{* *} 1$ to 7 drinks/week for all woman and men ages $>65$ years and 1 to 14 drinks/week for men $\leq 65$ years.

${ }^{+\dagger} \geq 8$ drinks/week for all woman and men ages $>65$ years and $\geq 15$ drinks/week for men $\leq 65$ years.

a "preferred" depression-screening instrument (ie, embedded in the KPNC electronic health record and integrated into the standardized algorithm for depression screening in primary care clinics); although the PHQ-9 is embedded in the KPNC electronic health record, it has not been adopted as 
Table 2. Adjusted Odds Ratios of Depression Screening Administration and Significant Depression among Primary Care Adult Patients Screened for Hazardous Alcohol Use*

\begin{tabular}{|c|c|c|c|c|}
\hline \multirow[b]{2}{*}{ Characteristic } & OR (95\% CI) & \multirow[b]{2}{*}{$P$ value } & \multirow{2}{*}{$\begin{array}{c}\text { OR }(95 \% \text { CI }) \\
\text { Significant } \\
\text { Depressive } \\
\text { Symptoms }{ }^{\dagger}\end{array}$} & \multirow[b]{2}{*}{$P$ value } \\
\hline & $\begin{array}{l}\text { Administered the } \\
\text { PHQ-9 }\end{array}$ & & & \\
\hline Female (reference group, male) & $1.67(1.59$ to 1.75$)$ & $<.001$ & $1.11(1.06$ to 1.17$)$ & $<.001$ \\
\hline \multicolumn{5}{|l|}{ Age, years (reference group, 18 to 39 ) } \\
\hline 40 to 65 & $0.77(0.73$ to 0.81$)$ & $<.001$ & $0.75(0.72$ to 0.78$)$ & $<.001$ \\
\hline$>65$ & $0.51(0.45$ to 0.57$)$ & $<.001$ & $0.47(0.43$ to 0.51$)$ & $<.001$ \\
\hline \multicolumn{5}{|l|}{$\begin{array}{l}\text { Race/ethnicity (reference group, } \\
\text { White) }^{\ddagger}\end{array}$} \\
\hline Asian & $0.45(0.42$ to 0.48$)$ & $<.001$ & $1.07(0.98$ to 1.16$)$ & .113 \\
\hline Black/African American & 0.75 (0.69 to 0.80$)$ & $<.001$ & $1.55(1.38$ to 1.75$)$ & $<.001$ \\
\hline Hispanic & $0.82(0.78$ to 0.87$)$ & $<.001$ & $1.29(1.20$ to 1.40$)$ & $<.001$ \\
\hline Other/Unknown & $0.78(0.75$ to 0.81$)$ & $<.001$ & $1.21(1.13$ to 1.30$)$ & $<.001$ \\
\hline Medicaid coverage & $1.25(1.15$ to 1.36$)$ & $<.001$ & $1.31(1.15$ to 1.48$)$ & $<.001$ \\
\hline $\begin{array}{l}\text { Nondepressive/non-SUD mental health } \\
\text { diagnosis }^{\S}\end{array}$ & $1.32(1.26$ to 1.39$)$ & $<.001$ & $0.96(0.90$ to 1.03$)$ & .310 \\
\hline Charlson comorbidity score $\|$ & $0.96(0.94$ to 0.98$)$ & $<.001$ & $1.03(1.01$ to 1.06$)$ & .003 \\
\hline \multicolumn{5}{|l|}{$\begin{array}{l}\text { Weekly alcohol use (reference group: } \\
\text { hazardous alcohol use) }\end{array}$} \\
\hline Abstinent & $0.72(0.67$ to 0.77$)$ & $<.001$ & $0.84(0.78$ to 0.90$)$ & $<.001$ \\
\hline Moderate alcohol use $\mathrm{e}^{\dagger \dagger}$ & $0.70(0.67$ to 0.74$)$ & $<.001$ & $0.71(0.66$ to 0.76$)$ & $<.001$ \\
\hline
\end{tabular}

CI, confidence interval; OR, odds ratio; PHQ-9, Patient Health Questionnaire 9; SUD, substance use disorder; ICD-9, International Classification of Diseases, ninth revision.

*Logistic generalized estimating equations accounting for patient nested within facility were applied to estimate population-level average effects.

${ }^{\dagger}$ Among patients who were administered the PHQ-9 ( $\left.\mathrm{n}=68,686\right)$.

${ }^{\ddagger}$ Race/ethnicity data were self-reported by patients during their intake evaluation.

${ }^{\S}$ Any ICD-9 visit diagnosis code within 1 year prior to the first Alcohol Drinking as a Vital Sign primary care visit that adhered to the following criteria was considered a positive diagnosis: any mental, behavioral and neurodevelopmental disorder (290.XX, 293.XX, 294.XX-302.9, or 306.XX-319), excluding depressive disorders (296.2X, 296.3X, 296.82, 298.0, 300.4, 301.12, 309.0, 309.1, 309.28, or 311), alcohol-related mental disorders (291.XX, 305.0X, or 303.0X), drug-induced mental disorders (292.XX), and nontobacco drug abuse or dependence (305.2X, 305.3X, 305.4X, 305.5X, 306.6X, 305.7X, 305.8X, 305.9X, or 304.XX), where "X" represents any positive integer.

|lORs correspond to a 1-point increment in the Charlson comorbidity score.

**Patients were asked to estimate alcohol use within the past 90 days; hazardous alcohol use was defined as $\geq 8$ drinks/week for all woman and men ages $>65$ years and $\geq 15$ drinks/week for men $\leq 65$ years.

${ }^{+\dagger} 1$ to 7 drinks/week for all woman and men ages $>65$ years and 1 to 14 drinks/week for men $\leq 65$ years.

a routine, systematic part of the adult primary care clinical workflow. In addition, clinicians may have used other methods to screen for depression, such as the PHQ- $2^{44}$ (which would have been administered in article format or verbally, as this measure is not integrated into the KPNC electronic health record) or unstructured assessment, neither of which would have been captured in our analysis. Furthermore, clinicians may not have administered the PHQ-9 to patients who were already exhibiting symptoms of depression or who previously met criteria for a depressive disorder. For these reasons, the absolute rate of depression screening we report is likely an underestimate; however, the relative rates of depression screening remain informative.

Specifically, the observed discrepancies between rates of depression screening and significant depressive symptoms by medical comorbidity burden and race/ethnicity deserve attention. Rates of depressive symptoms among those with chronic medical conditions, such as diabetes, ${ }^{45}$ are higher than those found in the general population and are frequently associated with worse treatment adherence $^{46}$ and lower quality of life. ${ }^{47}$ In contrast, recent epidemiologic studies suggest that adults with historically marginalized ethnic identities, such as those who are black or Latino, exhibit lower rates 
of depressive disorders ${ }^{48}$ and are less likely to receive psychiatric treatment than whites. ${ }^{49}$ Although our data do not indicate why these groups were less likely to complete (or to be offered) the PHQ-9, it is plausible that clinicians may have anticipated not having sufficient time to appropriately evaluate positive PHQ-9 screening results, to offer psychoeducation and brief counseling, and, if needed, to initiate treatment referral for patients in whom other chronic medical conditions compete for their attention during time-limited primary care appointments. Likewise, clinicians may have failed to detect culturally prescribed manifestations of depression among minority patients.

The results of this study should be interpreted in the context of several limitations. Our reliance on diagnostic codes may underestimate the prevalence of medical comorbidities and mental health diagnoses. In addition, limiting our analysis of depression screening to the PHQ-9 likely underestimates the absolute rate of depression screening in this sample. Future studies may use data-mining techniques to collect nonstandardized depression screenings in the electronic health record that were recorded in free-text format, for instance. Similarly, although a PHQ-9 total score threshold of 10 demonstrates good specificity and sensitivity in primary care settings compared with other self-report depression-symptom measures,${ }^{50}$ our study may have excluded patients who met criteria for major depression and included others who would not have met diagnostic criteria for major depression.

Our findings have important implications for the primary care setting. First, the low overall rate and relative rates of depression screening of certain groups (men, ethnic/racial minorities, more medically ill patients) highlight a specific area for system-wide improvement in primary care settings. Given the uneven distribution and poor access to mental health services for many groups in the United States, primary care can fill that gap if mechanisms for robust and systematic screening, treatment, and specialty treatment referral workflows are in place. Primary care physicians are increasingly prescribing psychotropic medications, ${ }^{51}$ which underscores the need for integration of primary and psychiatric care, such as the collaborative care model. ${ }^{52}$ Second, screening for and treating significant depression among primary care patients may improve the quality of medical care and de- crease the burden of physical illnesses given the impact of depression on medical care.

To see this article online, please go to: http://jabfm.org/content/ 31/5/724.full.

\section{References}

1. Brody DJ, Pratt LA, Hughes J. Prevalence of depression among adults aged 20 and over: United States, 2013-2016. NCHS Data Brief, no 303. Hyattsville, MD: National Center for Health Statistics; 2018. Available from: https://www.cdc.gov/nchs/data/ databriefs/db303.pdf. Accessed May 10, 2018.

2. Shim RS, Baltrus P, Ye J, Rust G. Prevalence, treatment, and control of depressive symptoms in the United States: results from the National Health and Nutrition Examination Survey (NHANES), 20052008. J Am Board Fam Med 2011;24:33-8.

3. Centers for Disease Control and Prevention (CDC). National Diabetes Statistics Report, 2017. US Department of Health and Human Services. 2017. Available from: https://www.cdc.gov/diabetes/pdfs/ data/statistics/national-diabetes-statistics-report.pdf. Accessed May 10, 2018.

4. Wittchen HU, Kessler RC, Beesdo K, Krause P, Hofler M, Hoyer J. Generalized anxiety and depression in primary care: prevalence, recognition, and management. J Clin Psychiatry 2002;63(Suppl 8): $24-34$.

5. DiMatteo MR, Lepper HS, Croghan TW. Depression is a risk factor for noncompliance with medical treatment: meta-analysis of the effects of anxiety and depression on patient adherence. Arch Intern Med 2000;160:2101-7.

6. Guccione AA, Felson DT, Anderson JJ, et al. The effects of specific medical conditions on the functional limitations of elders in the Framingham Study. Am J Public Health 1994;84:351-8.

7. Siu AL, US Preventive Services Task Force (USPSTF), Bibbins-Domingo K, et al. Screening for depression in adults: US Preventive Services Task Force recommendation statement. JAMA 2016;315: $380-7$.

8. Akincigil A, Matthews EB. National rates and patterns of depression screening in primary care: results from 2012 and 2013. Psychiatr Serv 2017;68:660-6.

9. Jonas DE, Garbutt JC, Amick HR, et al. Behavioral counseling after screening for alcohol misuse in primary care: a systematic review and meta-analysis for the U.S. Preventive Services Task Force. Ann Intern Med 2012;157:645-54.

10. Esser MB, Hedden SL, Kanny D, Brewer RD, Gfroerer JC, Naimi TS. Prevalence of alcohol dependence among US adult drinkers, 2009-2011. Prev Chronic Dis 2014;11:E206.

11. Fleming MF, Manwell LB, Barry KL, Johnson K. At-risk drinking in an HMO primary care sample: 
prevalence and health policy implications. Am J Public Health 1998;88:90-3.

12. Mertens JR, Weisner C, Ray GT, Fireman B, Walsh K. Hazardous drinkers and drug users in HMO primary care: prevalence, medical conditions, and costs. Alcohol Clin Exp Res 2005;29:989-98.

13. Friedmann PD. Clinical practice. Alcohol use in adults. N Engl J Med 2013;368:365-73.

14. Sacks JJ, Gonzales KR, Bouchery EE, Tomedi LE, Brewer RD. 2010 national and state costs of excessive alcohol consumption. Am J Prev Med 2015;49:e79.

15. Moyer VA, Preventive Services Task Force. Screening and behavioral counseling interventions in primary care to reduce alcohol misuse: U.S. preventive services task force recommendation statement. Ann Intern Med 2013;159:210-8.

16. National Institute on Alcohol Abuse and Alcoholism. Helping patients who drink too much: a clinician's guide. 2016;NIH Publication No. 07-3769. Available from: https://pubs.niaaa.nih.gov/publications/ Practitioner/CliniciansGuide2005/guide.pdf. Accessed January 29, 2018.

17. Saunders JB, Aasland OG, Babor TF, de la Fuente JR, Grant M. Development of the Alcohol Use Disorders Identification Test (AUDIT): WHO collaborative project on early detection of persons with harmful alcohol consumption-II. Addiction 1993;88: 791-804.

18. Bush K, Kivlahan DR, McDonell MB, Fihn SD, Bradley KA. The AUDIT alcohol consumption questions (AUDIT-C): an effective brief screening test for problem drinking. Ambulatory Care Quality Improvement Project (ACQUIP). Alcohol Use Disorders Identification Test. Arch Intern Med 1998; 158:1789-95.

19. Mitchell AJ, Meader N, Bird V, Rizzo M. Clinical recognition and recording of alcohol disorders by clinicians in primary and secondary care: meta-analysis. Br J Psychiatry 2012;201:93-100.

20. Rehm J, Anderson P, Manthey J, et al. Alcohol use disorders in primary health care: What do we know and where do we go? Alcohol 2016;51:422-7.

21. Grant BF, Goldstein RB, Saha TD, et al. Epidemiology of DSM-5 alcohol use disorder: results from the National Epidemiologic Survey on Alcohol and Related Conditions III. JAMA Psychiatry 2015;72: 757-66.

22. Hasin DS, Goodwin RD, Stinson FS, Grant BF. Epidemiology of major depressive disorder: results from the National Epidemiologic Survey on Alcoholism and Related Conditions. Arch Gen Psychiatry 2005;62:1097-106.

23. Sullivan LE, Fiellin DA, O'Connor PG. The prevalence and impact of alcohol problems in major depression: a systematic review. Am J Med 2005;118: 330-41.

24. Blow FC, Gillespie BW, Barry KL, Mudd SA, Hill EM. Brief screening for alcohol problems in elderly populations using the Short Michigan Alcoholism Screening Test-Geriatric Version (SMAST-G). Alcohol Clin Exp Res 1998;22(Suppl 3):131A.

25. Bartels SJ, Coakley E, Oxman TE, et al. Suicidal and death ideation in older primary care patients with depression, anxiety, and at-risk alcohol use. Am J Geriatr Psychiatry 2002;10:417-27.

26. Boden JM, Fergusson DM. Alcohol and depression. Addiction 2011;106:906-14.

27. Epstein JF, Induni M, Wilson T. Patterns of clinically significant symptoms of depression among heavy users of alcohol and cigarettes. Prev Chronic Dis 2009;6:A09.

28. Paljarvi T, Koskenvuo M, Poikolainen K, Kauhanen J, Sillanmaki L, Makela P. Binge drinking and depressive symptoms: a 5-year population-based cohort study. Addiction 2009;104:1168-78.

29. Skogen JC, Harvey SB, Henderson M, Stordal E, Mykletun A. Anxiety and depression among abstainers and low-level alcohol consumers. The Nord-Trondelag Health Study. Addiction 2009; 104:1519-29.

30. St John PD, Montgomery PR, Tyas SL. Alcohol misuse, gender and depressive symptoms in community-dwelling seniors. Int J Geriatr Psychiatry 2009; 24:369-75.

31. Watts M. Understanding the coexistence of alcohol misuse and depression. Br J Nurs 2008;17:696-9.

32. Watkins KE, Paddock SM, Zhang L, Wells KB. Improving care for depression in patients with comorbid substance misuse. Am J Psychiatry 2006;163: 125-32.

33. Burns L, Teesson M, O'Neill K. The impact of comorbid anxiety and depression on alcohol treatment outcomes. Addiction 2005;100:787-96.

34. Roeloffs CA, Wells KB, Ziedonis D, Tang L, Unutzer J. Problem substance use among depressed patients in managed primary care. Psychosomatics 2002;43:405-12.

35. Roeloffs CA, Fink A, Unutzer J, Tang L, Wells KB. Problematic substance use, depressive symptoms, and gender in primary care. Psychiatr Serv 2001;52:1251-3.

36. Mertens JR, Chi FW, Weisner CM, et al. Physician versus non-physician delivery of alcohol screening, brief intervention and referral to treatment in adult primary care: the ADVISe cluster randomized controlled implementation trial. Addict Sci Clin Pract 2015;10:26.

37. Kroenke K, Spitzer RL, Williams JB. The PHQ-9: validity of a brief depression severity measure. J Gen Intern Med 2001;16:606-13.

38. Manea L, Gilbody S, McMillan D. A diagnostic meta-analysis of the Patient Health Questionnaire-9 (PHQ-9) algorithm scoring method as a screen for depression. Gen Hosp Psychiatry 2015;37:67-75.

39. O'Connor E, Rossom RC, Henninger M, et al. Screening for depression in adults: an updated systematic evidence review for the U.S. Preventive Ser- 
vices Task Force. 2016;Evidence Synthesis No. 128. AHRQ Publication No. 14-05208-EF-1. Rockville, MD: Agency for Healthcare Research and Quality (US).

40. Arroll B, Goodyear-Smith F, Crengle S, et al. Validation of PHQ-2 and PHQ-9 to screen for major depression in the primary care population. Ann Fam Med 2010;8:348-53.

41. Charlson ME, Charlson RE, Peterson JC, Marinopoulos SS, Briggs WM, Hollenberg JP. The Charlson comorbidity index is adapted to predict costs of chronic disease in primary care patients. J Clin Epidemiol 2008;61:1234-40.

42. Charlson ME, Pompei P, Ales KL, MacKenzie CR. A new method of classifying prognostic comorbidity in longitudinal studies: development and validation. J Chronic Dis 1987;40:373-83.

43. Quan H, Sundararajan V, Halfon P, et al. Coding algorithms for defining comorbidities in ICD-9-CM and ICD-10 administrative data. Med Care 2005;43: 1130-9.

44. Kroenke K, Spitzer RL, Williams JB. The Patient Health Questionnaire-2: validity of a two-item depression screener. Med Care 2003;41:1284-92.

45. Roy T, Lloyd CE. Epidemiology of depression and diabetes: a systematic review. J Affect Disord 2012; 142 Suppl:S8-21.
46. Gonzalez JS, Peyrot M, McCarl LA, et al. Depression and diabetes treatment nonadherence: a metaanalysis. Diabetes Care 2008;31:2398-403.

47. Ali S, Stone M, Skinner TC, Robertson N, Davies M, Khunti K. The association between depression and health-related quality of life in people with type 2 diabetes: a systematic literature review. Diabetes Metab Res Rev 2010;26:75-89.

48. Smith SM, Stinson FS, Dawson DA, Goldstein R, Huang B, Grant BF. Race/ethnic differences in the prevalence and co-occurrence of substance use disorders and independent mood and anxiety disorders: results from the National Epidemiologic Survey on Alcohol and Related Conditions. Psychol Med 2006; 36:987-98.

49. Ault-Brutus AA. Changes in racial-ethnic disparities in use and adequacy of mental health care in the United States, 1990-2003. Psychiatr Serv 2012;63: 531-40.

50. Hirschtritt ME, Kroenke K. Screening for depression. JAMA 2017;318:745-6.

51. Olfson M, Kroenke K, Wang S, Blanco C. Trends in office-based mental health care provided by psychiatrists and primary care physicians. J Clin Psychiatry 2014;75:247-53.

52. Archer J, Bower P, Gilbody S, et al. Collaborative care for depression and anxiety problems. Cochrane Database Syst Rev 2012;10:CD006525. 